\title{
Development of health and depressive symptoms among Danish adolescents-Socioeconomic differences and effects of life-style
}

\author{
Johan Hviid Andersen ${ }^{1}$, Merete Labriola ${ }^{1,2^{\star}}$, Thomas Lund ${ }^{1,3}$, Claus D. Hansen ${ }^{1,4}$ \\ ${ }^{1}$ Danish Ramazzini Centre, Department of Occupational Medicine, Regional Hospital Herning, Herning, Denmark; \\ *Corresponding Author: merlab@,rm.dk \\ ${ }^{2}$ Department of Clinical Social Medicine, Public Health and Quality Management, Central Denmark Region and Section of Clinical \\ Social Medicine \& Rehabilitation, School of Public Health, University of Aarhus, Aarhus, Denmark \\ ${ }^{3}$ National Centre for Occupational Rehabilitation, Rauland, Norway \\ ${ }^{4}$ Department of Sociology \& Social Work, Aalborg University, Aalborg, Denmark
}

Received 19 November 2012; revised 20 December 2012; accepted 28 December 2012

\begin{abstract}
While the existence of social inequality in health in childhood as well as among adults is well established, research of mechanisms underlying this inequality is still sparse. The study aim was to report on the development of self-rated health and depressive symptoms from age 15 to 18 years in a cohort study of Danish adolescents. Methods: The cohort comprised 3,681 individuals born in 1989, 3058 individuals answered the baseline questionnaire in 2004, and 2400 responded to a follow-up questionnaire in 2007, with 2181 individuals participating in both rounds ( $59 \%$ of the original cohort). Social background information of the participants was derived from a national register. For the analysis two variables indicating change in the two health indicators was computed by subtracting the 2007 levels of the variables from the levels experienced in 2004. Results: After 3 years, mean self-rated health (SRH) deteriorated slightly in adolescents $(-0.24 ; 95 \% \mathrm{Cl}=-0.28$ to -0.19$)$ across all socioeconomic status (SES) groups and depressive symptoms increased $(0.64 ; 95 \%$ $\mathrm{Cl}=0.52$ to 0.75$)$. High household income was protective for decrease in SRH (0.62; $0.43-0.91)$. Negative life-style changes were associated with poorer SRH and more depressive symptoms. Conclusions: Self-rated health and depressive symptoms changed to the worse among Danish adolescents from age 15 to 18 years. Negative changes in several lifestyle factors were found to accompany the deterioration of health. This result stresses the intrinsic relationship between lifestyle changes and health and the pos-
\end{abstract}

sible positive effect of maintaining and enhancing positive lifestyle factors.

Keywords: Longitudinal Cohort Study; Lifestyle; Self-Rated Health; Depressive Symptoms

\section{INTRODUCTION}

Whilst social inequality in childhood and adult health is well established, research into the mechanisms underlying this inequality is essential if we are to understand how social and economic factors are related to health and where interventions will be effective. Assessments of individual overall health status have been widely studied by means of self-rated health (SRH), originally developed for the ShortForm-36 (SF-36) and SF-12. In adult populations, this single self-perception measure has revealed systematic associations with later morbidity, mortality and disability [1,2]. Despite a large body of work examining adult SRH, only a few studies have evaluated the role of SRH among adolescents as a measure of actual health status.

Among US adolescents' self-rated health was found to be moderately stable and was characterized as an enduring self-concept among adolescents [3]. The Norwegian young-Hunt study followed adolescents aged $13-19$ years for 4 years and found that SRH was a relatively stable construct during adolescence and that it was related to both general well-being and disability as well as to use of healthcare, and health-compromising behaviours. The study, however, lacked information on family income and parents' educational level rendering socioeconomic comparisons impossible [4].

The German Bella-study [5] found children from lower social status homes to report a lower health-related quality of life compared to children from middle social 
status homes, who, in turn, were surpassed by children with a high family social status. Various mechanisms that could explain the relationship between socioeconomic status, and the well-being and health-related quality of life of children and adolescents are being widely discussed in the literature [6-10]. Many of the hypothesized mechanisms refer to differences in access to material and social resources or to reactions to stress-induced conditions to which children and adolescents are exposed. One of the most prominent explanations of social inequality of health is the behavioural/cultural explanation that hypothesize that the observed health differentials are primarily the result of social class differences in health related lifestyle behaviours [6].

Depression is another commonly studied measure of health and wellbeing among adolescents and young adults [11-15]. First onset is usually in adolescence [11-12]. Depression early in life can have serious implications for the individuals' school performance, school absence and dropout and later professional careers [14]. Furthermore, depression in adolescence can increase use of tobacco and alcohol [15]. Other studies have shown a moderate association between physical activity and depression amongst adolescents $[16,17]$. However, due to cross sectional designs, the causal relation between depression and physical activity is unclear.

This study reports on the development of self-rated health and depressive symptoms, from age 15 to 18 , in a prospective cohort study among Danish adolescents. The aim was to study life-style related predictors for health change among children with different social backgrounds defined by household income and parents' education.

\section{METHODS}

\subsection{Study Population}

Data were gathered as part of the ongoing West Jutland Cohort Study (VestLiv), which is a survey following a complete regional cohort of adolescents in the Western part of Denmark, gathering comprehensive information on the occurrence, severity and impact of manifold symptoms of physical and mental health problems - both self-reported and register-based [18]. Information on socioeconomic status of parents is from official registers.

The cohort comprised of 3681 individuals born in 1989, of which 3058 answered the baseline questionnaire in 2004 , resulting in a response rate of $83 \%$. Everyone who had not opted out of the study $(\mathrm{N}=3293)$ was sent the second round questionnaire in 2007, and 2400 answered the questionnaire resulting in a response rate of $73 \% ; 2181$ individuals participated in both rounds $(59 \%$ of the original cohort). These 2181 individuals constitute the basis of analysis in this study.
Information on the social background of the participants (e.g. household income, parents' highest education etc) derived from a national register in Statistics Denmark by using information from the Central Office of Civil Registration (CPR) in which the respondents are linked to their legal parents or guardians via a personal identification number given to everyone in Denmark at birth (or upon entry for immigrants).

Ethical approval: The study has been notified to and registered by Datatilsynet (the Danish Data Protection Agency). According to Danish law, questionnaire and register-based studies do not need approval by ethical and scientific committees, nor informed consent.

\subsection{Health Indicators}

This study examines two aspects of adolescents' health status: self-rated health (SRH), and psychological health. For SRH the question was "In general, how would you rate your health?" with response options from 1 "Poor" to 5 "Excellent." Psychological health was measured using the Center for Epidemiological Studies Depression Scale for Children (CES-DC), 4-item version [19]. Responses were scored 0 "Not At All", 1 "A Little", 2 "Some", 3 "A Lot".

\subsection{Independent Variables}

Socioeconomic status (SES) was defined according to household income and parents' educational level in the year before baseline (2003). Household income was divided into quartiles, and parents' highest education was divided into four levels: under 10 years, 10 - 12 years, 13 - 15 years and $>15$ years of education.

Life-style factors were measured by a series of questions on leisure-time and sporting activities, smoking habits, time spent watching television and using a computer, and eating habits at age 15 and 18 years. We constructed dichotomous variables for a change in lifestyle indicating a potentially negative change versus no change/change to a healthier life-style during the 3-year follow-up period e.g. starting smoking versus continuing to smoke/stopping smoking. Characteristics of the study population at baseline 2004 are described in Table 1.

\subsection{Statistics}

Adolescents who participated in both waves of the study (2004 and 2007) were eligible for data analysis (n = 2181). For the analysis, two variables indicating a change in the two health indicators was computed by subtracting the 2007 levels from the level reported in 2004. These are the dependent variables. A decrease of at least one scale point on a scale from 1 to 5 was considered a relevant change for SRH, and for CES-DC scale, which runs from 0 to 12 , a change of at least 3 scale- 
Table 1. Characteristics of study population at baseline 2004 and at follow up 2007, and changes in negative direction for included variables from 2004 to 2007 .

\begin{tabular}{|c|c|c|c|c|}
\hline & & 2004 & 2007 & $2004 / 2007$ \\
\hline Variable & Level & $\mathrm{N}(\%)$ & $\mathrm{N}(\%)$ & $\mathrm{N}(\%)$ \\
\hline \multirow[t]{2}{*}{ Gender } & Female & $1180(54.1)$ & & \\
\hline & Male & $1001(45.9)$ & & \\
\hline \multirow[t]{5}{*}{ Self-rated health (SRH) } & Excellent & $645(29.8)$ & $477(22.5)$ & \\
\hline & Very good & $999(46.1)$ & $909(42.8)$ & \\
\hline & Good & $442(20.4)$ & $608(28.6)$ & \\
\hline & Fair & $76(3.5)$ & $138(6.5)$ & \\
\hline & Poor & $6(0.3)$ & $21(1.0)$ & \\
\hline Poorer SRH at follow-up & Decrease of $\geq 1$ point & & & $780(35.8)$ \\
\hline \multirow[t]{2}{*}{ Depress. symptoms (score 0 - 12) } & $0-3$ & $1665(78.5)$ & $1446(67.1)$ & \\
\hline & $4-12$ & $455(21.5)$ & $708(32.9)$ & \\
\hline More depressive at follow up & Increase of $\geq 3$ point & & & $465(24.3)$ \\
\hline \multirow[t]{4}{*}{ Parental educational level } & $<10 \mathrm{yrs}$ & $214(9.8)$ & & \\
\hline & $10-12 \mathrm{yrs}$ & $1107(50.8)$ & & \\
\hline & $13-15$ yrs & $709(32.5)$ & & \\
\hline & $>15 \mathrm{yrs}$ & $138(6.3)$ & & \\
\hline \multirow[t]{4}{*}{ Household income, EURO } & $<60,000$ & $473(21.7)$ & & \\
\hline & $60-75,000$ & $533(24.4)$ & & \\
\hline & $75-90,000$ & $573(26.3)$ & & \\
\hline & $>90,000$ & $590(27.1)$ & & \\
\hline \multirow[t]{6}{*}{ Participation in sports, hrs/week } & 0 & $32(1.5)$ & $99(4.6)$ & \\
\hline & Approx. 0.5 & $84(3.9)$ & $102(4.7)$ & \\
\hline & Approx. 1 & $214(9.8)$ & $295(13.6)$ & \\
\hline & Approx. 2 - 3 & $565(25.9)$ & $668(30.7)$ & \\
\hline & Approx. 4 - 6 & $756(34.7)$ & $649(29.8)$ & \\
\hline & 7 or more & $511(23.4)$ & $360(16.6)$ & \\
\hline Reduction in sports & & & & $338(15.5)$ \\
\hline \multirow[t]{4}{*}{ Smoking habits } & Non smoker & $1889(89.2)$ & $1555(73.5)$ & \\
\hline & $<$ Once/week & $94(4.4)$ & $158(7.5)$ & \\
\hline & Not daily, but >once/week & $39(1.8)$ & $98(4.6)$ & \\
\hline & Daily & $94(4.4)$ & $305(14.4)$ & \\
\hline Begun to smoke & & & & $386(17.7)$ \\
\hline \multirow[t]{2}{*}{ TV/video and computer use } & $<2$ hrs/day & $913(42.3)$ & $470(22.0)$ & \\
\hline & $2 \mathrm{hrs}+/$ day & $1246(57.7)$ & $1668(78.0)$ & \\
\hline More TV and computer use & & & & $1435(65.8)$ \\
\hline \multirow[t]{3}{*}{ Fruit/vegetable intake } & Once/day or more & $849(39.2)$ & $310(14.6)$ & \\
\hline & Once or more/week & 727 (33.5) & $752(35.4)$ & \\
\hline & $<$ Once/week & $589(27.2)$ & $1061(50.0)$ & \\
\hline Less fruit/vegetable & & & & $1,106(33.7)$ \\
\hline \multirow[t]{3}{*}{ Wholegrain bread intake } & Once/day or more & $645(30.4)$ & $667(31.5)$ & \\
\hline & Once or more/week & $956(45.0)$ & $798(37.6)$ & \\
\hline & $<$ Once/week & $523(24.6)$ & $653(30.9)$ & \\
\hline Less full grain bread & & & & $535(24.5)$ \\
\hline
\end{tabular}


points, corresponding to 1 standard deviation, was used to indicate change. Logistic regression analyses were conducted with the two measures of SES, life style factors, and gender as the independent variables. Results are reported as odds ratios (OR) with $95 \%$ confidence intervals $(95 \% \mathrm{CI})$ for developing poorer self-rated health and more depressive symptoms in the 3-year follow-up period. Baseline levels of the two outcomes and all the life-style factors were included in the models in order to adjust for baseline levels. The Hosmer-Lemeshow Goodness-of-fit test was used for each of the logistic regression models.

\section{RESULTS}

Assessments of health behaviour at baseline 2004 and at follow up 2007 show changes in negative direction for all included variables (Table 1).

Furthermore, mean self-rated health (SRH) deteriorated slightly in adolescents from 15 to 18 years $(-0.24$; $95 \% \mathrm{CI}=-0.28$ to -0.19 ) across all SES groups (Table 2) and depressive symptoms increased $(0.64 ; 95 \% \mathrm{CI}=$ 0.52 to 0.75 ) during the 3 years (Table 3 )

Parental education level was not associated with a deterioration in SRH or increase in depressive symptoms among adolescents from 15 to 18 years of age, whereas there was a tendency for adolescents from lower income homes to develop poorer SRH: Higher household income was protective against reporting poorer SRH after 3 years $(\mathrm{OR}=0.62 ; 95 \% \mathrm{CI} 0.43-0.91)$, but had no effect on the development of depressive symptoms. Female adolescents had a two-fold risk of developing worse $\mathrm{SRH}$ and more symptoms of depression in the 3-year period compared to males (Table 4).

Changes in several of the life-style factors were associated with poorer SRH in the follow-up period. Adolescents who reduced their sporting activities $(\mathrm{OR}=1.97$; 1.46 - 2.66) or decreased their intake of fruit and vegetables $(1.36 ; 1.06$ - 1.73) had poorer SRH after 3 years. More than two thirds of the respondents $(65.8 \%)$ had increased their time with television and computer use, and this was associated with poorer $\mathrm{SRH}(\mathrm{OR}=1.58$; 1.23 - 2.02). A reduction in fruit and vegetable intake and of whole-grain bread were each associated with a $48 \%$ increased risk of reporting more depressive symptoms after 3 years, whereas the association between eating habits and SRH after 3 years was smaller (Table 4). Finally, reducing sports activities was associated with poorer SRH and more symptoms of depression from age 15 to 18 . Those who begun to smoke reported poorer SRH $(\mathrm{OR}=1.81 ; 1.36-2.42)$ at follow-up (Table 4).

\section{DISCUSSION}

In general, development in self-rated health and depressive symptoms were in a negative direction among

Table 2. Self-Rated Health (SRH) at baseline (2004) and follow-up (2007). N = 2140.

\begin{tabular}{|c|c|c|c|c|c|c|c|}
\hline \multirow{2}{*}{\multicolumn{2}{|c|}{ Self-rated health ${ }^{*}$}} & \multicolumn{6}{|c|}{ Follow-up 2007} \\
\hline & & Excellent & Very good & Good & Not very good & Poor & Total \\
\hline \multirow{6}{*}{ Baseline 2004} & Excellent & $261(12.2 \%)$ & $262(12.2 \%)$ & $99(4.6 \%)$ & $14(0.7 \%)$ & $2(0.1 \%)$ & $638(29.8 \%)$ \\
\hline & Very good & $174(8.1 \%)$ & $479(22.4 \%)$ & $282(13.2 \%)$ & $41(1.9 \%)$ & $10(0.5 \%)$ & $986(46.1 \%)$ \\
\hline & Good & $34(1.6 \%)$ & $145(6.8 \%)$ & $191(8.9 \%)$ & $61(2.9 \%)$ & $5(0.2 \%)$ & $436(20.4 \%)$ \\
\hline & Not very good & $4(0.29 \%)$ & $18(0.8 \%)$ & $29(1.4 \%)$ & $20(0.9 \%)$ & $4(0.2 \%)$ & $75(3.5 \%)$ \\
\hline & Poor & $1(0.1 \%)$ & $1(0.1 \%)$ & $2(0.1 \%)$ & $1(0.1 \%)$ & 0 & $5(0.2 \%)$ \\
\hline & Total & $474(22.2 \%)$ & $905(42.3 \%)$ & $603(28.2 \%)$ & 137 (6.4\%) & $21(1.0 \%)$ & $2140(100 \%)$ \\
\hline
\end{tabular}

*Mean change estimate; $95 \%$ CI, t-test p-value, All: $-0.24 ;-0.28$ to $-0.19, \mathrm{p}<0.000$. Scale range $1-5$, Boys/girls: $0.06 ;-0.03$ to $0.14, p=0.09$.

Table 3. Depressive symptoms at baseline (2004) and follow-up (2007). N = 2120.

\begin{tabular}{lcccc}
\hline & & & \multicolumn{3}{c}{ Follow-up 2007 } \\
\cline { 2 - 4 } & Depressive symptoms & & Total \\
\hline \multirow{2}{*}{$\begin{array}{c}\text { Baseline } \\
2004\end{array}$} & Scale score 0 to 3 & Scale score 0 to 3 & Scale score 4 to 12 & $1,665(78.5 \%)$ \\
& Scale score 4 to 12 & $1197(56.5 \%)$ & $468(22.1 \%)$ & $455(21.5 \%)$ \\
& Total & $227(10.7 \%)$ & $228(10.8 \%)$ & $2120(100 \%)$ \\
\hline
\end{tabular}

"Mean change estimate; $95 \%$ CI, t-test p-value; All: 0.64; 0.52 to 0.75, $\mathrm{p}<0.000$. Scale range 0 - 12; Boys/girls: 0.30; 0.07 to $0.52, \mathrm{p}=0.005$. 
Table 4. Parental socioeconomic status (SES) and change in life-style factors-effects on the risk of developing poorer general health and more depressive symptoms in a 3-year follow up period amongst Danish adolescents. Logistic regression with odds ratios (OR) with $95 \%$ confidence interval $(\mathrm{CI}) . \mathrm{N}=2181$.

\begin{tabular}{|c|c|c|c|c|c|c|}
\hline \multirow[b]{2}{*}{ Variable } & \multirow[b]{2}{*}{ Level } & \multirow[b]{2}{*}{$\mathrm{N}(\%)$} & \multicolumn{2}{|c|}{ Poorer self-rated health } & \multicolumn{2}{|c|}{ More depressive symptoms } \\
\hline & & & $\begin{array}{c}\text { Partly adjusted } \\
\text { OR; } 95 \% \text { CI }\end{array}$ & $\begin{array}{c}\text { Fully adjusted }^{* *} \\
\text { OR; } 95 \% \text { CI }\end{array}$ & $\begin{array}{l}\text { Partly adjusted }^{*} \\
\text { OR; } 95 \% \text { CI }\end{array}$ & $\begin{array}{c}\text { Fully adjusted } \\
\text { OR; } 95 \% \text { CI }\end{array}$ \\
\hline \multirow{4}{*}{ Educational level } & Up to $10 \mathrm{yrs}$ & $214(9.9 \%)$ & 1.00 & 1.00 & 1.00 & 1.00 \\
\hline & $10-12 \mathrm{yrs}$ & $1107(51.1 \%)$ & $\begin{array}{c}0.89 \\
0.63-1.26\end{array}$ & $\begin{array}{c}0.88 \\
0.59-1.31\end{array}$ & $\begin{array}{c}0.87 ; \\
0.59-1.28\end{array}$ & $\begin{array}{c}0.89 \\
0.58-1.37\end{array}$ \\
\hline & $13-15 \mathrm{yrs}$ & $709(32.7 \%)$ & $\begin{array}{c}1.04 \\
0.72-1.50\end{array}$ & $\begin{array}{c}1.07 \\
0.70-1.63\end{array}$ & $\begin{array}{c}1.02 \\
0.68-1.55\end{array}$ & $\begin{array}{c}1.13 \\
0.71-1.79\end{array}$ \\
\hline & $>15 \mathrm{yrs}$ & $138(6.4 \%)$ & $\begin{array}{c}1.10 \\
0.66-1.83\end{array}$ & $\begin{array}{c}1.22 \\
0.69-2.17\end{array}$ & $\begin{array}{c}1.36 \\
0.78-2.36\end{array}$ & $\begin{array}{c}1.39 \\
0.71-2.61\end{array}$ \\
\hline \multirow{4}{*}{$\begin{array}{l}\text { Household income, } \\
\text { quartiles-EURO }\end{array}$} & $<60,000$ & $473(21.8 \%)$ & 1.00 & 1.00 & 1.00 & 1.00 \\
\hline & $60,000-75,000$ & $533(24.6 \%)$ & $\begin{array}{c}0.73 \\
0.52-1.02\end{array}$ & $\begin{array}{c}0.67 \\
0.46-0.98\end{array}$ & $\begin{array}{c}1.07 \\
0.73-1.56\end{array}$ & $\begin{array}{c}1.18 \\
0.77-1.81\end{array}$ \\
\hline & $75,000-90,000$ & $573(26.4 \%)$ & $\begin{array}{c}0.78 \\
0.56-1.09\end{array}$ & $\begin{array}{c}0.79 \\
0.54-1.14\end{array}$ & $\begin{array}{c}1.07 \\
0.73-1.56\end{array}$ & $\begin{array}{c}1.15 \\
0.75-1.76\end{array}$ \\
\hline & $>90,000$ & $590(27.2 \%)$ & $\begin{array}{c}0.62 \\
0.44-0.88\end{array}$ & $\begin{array}{c}0.62 \\
0.43-0.91\end{array}$ & $\begin{array}{c}0.87 \\
0.59-1.28\end{array}$ & $\begin{array}{c}0.94 \\
0.61-1.46\end{array}$ \\
\hline Gender & Female & $1180(54.1 \%)$ & $\begin{array}{c}1.66 \\
1.36-2.02\end{array}$ & $\begin{array}{c}1.76 \\
1.38-2.24\end{array}$ & $\begin{array}{c}2.03 ; \\
1.63-2.53\end{array}$ & $\begin{array}{c}2.37 \\
1.79-3.13\end{array}$ \\
\hline Reduction in sport & & $338(15.5 \%)$ & & $\begin{array}{c}1.97 \\
1.46-2.66\end{array}$ & & $\begin{array}{c}1.51 \\
1.09-2.11\end{array}$ \\
\hline Begun to smoke & & $386(17.7 \%)$ & & $\begin{array}{c}1.81 \\
1.36-2.42\end{array}$ & & $\begin{array}{c}1.25 \\
0.93-1.69\end{array}$ \\
\hline More TV and PC time & & $1435(65.8 \%)$ & & $\begin{array}{c}1.58 \\
1.23-2.02\end{array}$ & & $\begin{array}{c}1.09 \\
0.96-1.24\end{array}$ \\
\hline Less fruit and vegetables & & $1106(33.7 \%)$ & & $\begin{array}{c}1.36 \\
1.06-1.73\end{array}$ & & $\begin{array}{c}1.48 \\
1.12-1.94\end{array}$ \\
\hline Less wholegrain bread & & $535(24.5 \%)$ & & $\begin{array}{c}1.19 \\
0.91-1.55\end{array}$ & & $\begin{array}{c}1.47 \\
1.10-1.97\end{array}$ \\
\hline
\end{tabular}

"Adjusted for parents' educational level, household income, baseline self-rated health or depressive symptoms and gender, ${ }^{* *}$ Adjusted for parents' educational level, household income, baseline self-rated health or depressive symptoms, gender and life-style changes.

Danish adolescents from age 15 to 18 years. The risk of reporting poorer SRH after 3 years was lower in households with higher income, whereas parental educational level was not associated with the development in SRH or depressive symptoms. Adolescents who had adjusted certain life-style factors in a negative direction from the age of 15 to 18 reported poorer SRH and more depressive symptoms. These results are consistent with what has been observed in other longitudinal studies of health related lifestyle among adolescents [20,21].

Despite the relatively high average household income in this region of Denmark adolescents from households within the lowest quartile of incomes had a statistically significant increased risk of reporting poorer SRH after the three-year period. SRH is a measure of perception of general health rather than a measure of "true health", but such a measure seems indeed impossible to pinpoint [22]. Explanations for the effect of household income on health have been hypothesized as the direct effects of material living conditions (absolute deprivation) as well as to social comparisons and experiences of relative deprivation. The results from a meta-analysis and several other studies among adults suggest a moderate adverse effect of income inequality on health, but the population impact might be large [23,24]. A British study found that low household income was associated with lower SRH and a number of other indicators of poor health among children aged 5 - 15 years [25].

The discrepancy in findings related to the two measure of SES (household income and parents' highest education) emphasize that these are two different indicators of social status emphasizing different aspects-material versus cognitive dimensions of socioeconomic status [18]. From our results it seems that material circumstances better predict developments in SRH compared to parental educational level.

Developing more health-compromising habits from age 15 to 18 years was consistently associated with re- 
porting both poorer SRH and, to a lesser extent, more depressive symptoms in this group of adolescents. Even though the study was prospective there could be reverse causation in that, for example, a reduction in sporting activities could be due to developing poorer SRH and more depressive symptoms in the 3-year period. We tested for an association between changes in healthcompromising habits as the outcome variables using SRH and depressive symptoms as explanatory variables, and found several significant associations indicating that causation was bidirectional. The protective effect of positive health behaviour is in line with similar findings suggested in previous cross sectional studies [16,26,27]. Health-compromising behaviors and a lack of sporting activity and exercise were also found to be risk factors for deterioration in SRH in the Young-Hunt-Study, which benefits from a 4-year observation period [4]. We conclude that health risk behaviours, such as lack of leisure time sporting activity and smoking may contribute to later poor self-rated health. This has also been found to be true over a follow-up period of 25 years [28]. But in addition, developing more depressive symptoms and experiencing a deterioration in SRH may also result in health-compromising behaviours. This study benefits from using register-based information on parents education and household income. Comparing non-responders at baseline and dropouts in the follow-up period it can be seen that there were more non-responders and dropouts from households with low income and the least parental educational. This selection would tend to bias the results towards the null.

From a public health perspective, this study supports the idea that increasing sporting activities and providing better opportunities for healthy nutrition in schools will improve chances for the successful prevention of the development of poorer health among adolescents. A recent Cochrane review [29] found that there is some evidence of positive effects on lifestyle behaviors and physical health status measures, and that ongoing physical activity promotion in schools is recommended.

The study also points to the importance of giving special attention to adolescents who develop more depressive symptoms or experience a deterioration in SRH: this group may be at greater risk of developing a health compromising lifestyle to put their health at further risk.

This research received no specific grant from any funding agency in the public, commercial, or not-forprofit sectors.

\section{REFERENCES}

[1] Manderbacka, K. Lahelma, F. and Martikainen, P. (1998) Examining the continuity of self-rated health. International Journal of Epidemiology, 27, 208-213. doi:10.1093/ije/27.2.208

[2] Nielsen, A.B.S., Siersma, V. and Hiort, L.C., Drivsholm, T. Kreiner, S. and Hollnagel, H. (2008) Self-rated general health among 40-year-old Danes and its association with all-cause mortality at 10-, 20-, and 29 years' follow-up. Scand Journal of Public Health, 36, 3-11. doi: $10.1177 / 1403494807085242$

[3] Boardman, J.D. (2006) Self-rated health among US adolescents. Journal of Adolescent Health, 38, 401-408. doi:10.1016/j.jadohealth.2005.01.006

[4] Breidablik, H.J. Meland, E. and Lydersen, S. (2009) Self-rated health during adolescence: Stability and predictors of change (Young-Hunt study, Norway). European Journal of Public Health, 19, 73-78. doi:10.1093/eurpub/ckn111

[5] Ravens-Sieberer, U., Erhart, M., Wille, N. and Bullinger, M. (2008) Health-related quality of life in children and adolescents in Germany: Results of the BELLA study. European Child \& Adolescent Psychiatry, 17, 148-156. doi:10.1007/s00787-008-1016-X

[6] Elstad, JI. (2010) Indirect health-related selection or social causation? Interpreting the educational differences in adolescent health behaviours. Social Theory \& Health, 8 , 134-150. doi:10.1057/sth.2009.26

[7] Belfer, M.L. (2008) Child and adolescent mental disorders: The magnitude of the problem across the globe. Journal of Child Psychology and Psychiatry, 49, 226-236. doi:10.1111/j.1469-7610.2007.01855.x

[8] World Health Organization (2001) The World health report. Mental health: New understanding, new hope. WHO, Geneva. http://www.who.int/whr/2001/en/whr01 en.pdf

[9] Costello, E.J. Egger, H. and Angold, A. (2005) 10-year research update review: The epidemiology of child and adolescent psychiatric disorders: I. Methods and public health burden. Journal of the American Academy of Child \& Adolescent Psychiatry, 44, 972-986. doi:10.1097/01.chi.0000172552.41596.6f

[10] Patel, V., Flisher, A.J., Hetrick, S. and McGorry, P. (2007) Mental health of young people: A global public-health challenge. Lancet, 369, 1302-1313. doi:10.1016/S0140-6736(07)60368-7

[11] Birmaher, B., Ryan, N.D., Williamson, D.E., Brent, D.A. and Kaufman, J. (1996) Childhood and adolescent depression: A review of the past 10 years. Part II. Journal of the American Academy of Child and Adolescent Psychiatry, 35, 1575-1583. doi:10.1097/00004583-199612000-00008

[12] Clarke, G.N. Hornbrook, M., Lynch, F., Polen, M., Gale, J., Beardslee, W., O'Connor, E. and Seeley, J. (2001) A randomized trial of a group cognitive intervention for preventing depression in adolescent offspring of depressed parents. Archives of General Psychiatry, 58, 1127-1134. doi:10.1001/archpsyc.58.12.1127

[13] Lewinsohn, P.M. and Clarke, G.N. (1999) Psychosocial treatments for adolescent depression. Clinical Psychology Review, 19, 329-342. doi:10.1016/S0272-7358(98)00055-5

[14] Dopheide, J.A. (2006) Recognizing and treating depres- 
sion in children and adolescents. American Journal of Health-System Pharmacy, 63, 233-243.

doi:10.2146/ajhp050264

[15] Glied, S. and Pine, D.S. (2002) Consequences and correlates of adolescent depression. Archives of Pediatrics \& Adolescent Medicine, 156, 1009-1014.

[16] Wiles, N.J., Haase, A.M., Lawlor, D.A., Ness, A. and Lewis, G. (2012) Physical activity and depression in adolescents: Cross-sectional findings from the ALSPAC cohort. Social Psychiatry and Psychiatric Epidemiology, 47, 1023-1033. doi:10.1007/s00127-011-0422-4

[17] Babiss, L.A. and Gangwisch, J.E. (2009) Sports participation as a protective factor against depression and suicidal ideation in adolescents as mediated by self-esteem and social support. Journal of Developmental and Behavioral Pediatrics, 30, 376-384. doi:10.1097/DBP.0b013e3181b33659

[18] Christiansen, M., Hansen, C.D., Glasscock, D., et al. (2010) Social inequality and health in adolescents. Ugeskrift for Laeger, 172, 857-863.

[19] Fendrich, M. Weissman, M.M. and Warner, V. (1990) Screening for depressive disorder in children and adolescents: Validating the center for epidemiologic studies depression scale for children. American Journal of Epidemiology, 131, 538-551.

[20] Salonna, F. van Dijk, J.P., Geckova, A.M., Sleskova, M., Groothoff, J.W. and Reijneveld, S.A. (2008) Social inequalities in changes in health-related behaviour among Slovak adolescents aged between 15 and 19: A longitudinal study. BMC Public Health, 8, 57. doi:10.1186/1471-2458-8-57

[21] Friestad, C. and Klepp, K.N. (2006) Socioeconomic status and health behaviour patterns through adolescence: Results from a prospective cohort study in Norway. European Journal of Public Health, 16, 41-47. doi:10.1093/eurpub/cki051
[22] Huisman, M. and Deeg, D.J. (2010) A commentary on Marja Jylhä's "What is self-rated health and why does it predict mortality? Towards a unified conceptual model" (69:3, 2009, 307-316). Social Science \& Medicine, 70, 652-654. Dissussion 655-657. Epub 2009 November 26

[23] Kondo, N., Sembajwe, G., Kawachi, I., Van dam, R.M, Subramanian, S.V. and Yamagate, Z. (2009) Income inequality, mortality, and self-rated health: Meta-analysis of multilevel studies. British Medical Journal, 10, 339.

[24] Hildebrand, V. and Van Kerm, P. (2009) Income inequality and self-rated health status: Evidence from the European community household panel. Demography, 46, 805-825. doi:10.1353/dem.0.0071

[25] Emerson, E., Graham, H. and Hatton, C. (2006) Household income and health status in children and adolescents in Britain. European Journal of Public Health, 16, 354-360. doi:10.1093/eurpub/cki200

[26] Afifi, M. (2006) Positive health practices and depressive symptoms among highschool adolescents in Oman. Singapore Medical Association, 47, 960-966.

[27] Babiss, LA. and Gangwisch, J.E. (2009) Sports participation as a protective factor against depression and suicidal ideation in adolescents as mediated by self-esteem and social support. Society for Behavioral Pediatrics, 30, 376-384. doi:10.1097/DBP.0b013e3181b33659

[28] Svedberg, P., Bardage, C., Sandin, S. and Pedersen, N.L. (2006) A prospective study of health, life-style and psychosocial predictors of self-rated health. European Journal of Epidemiology, 21, 767-776. doi:10.1007/s10654-006-9064-3

[29] Dobbins, M., De Corby, K., Robeson, P., Husson, H. and Tirlis, D. (2009) School-based physical activity programs for promoting physical activity and fitness in children and adolescents aged 6-18. Cochrane Database of Systematic Reviews, 1, Article ID: CD007651. 